\title{
FONTES E DOSES DE NITROGÊNIO E ALTERAÇÕES NOS ATRIBUTOS QUÍMICOS DE UM LATOSSOLO CULTIVADO COM CAPIM-MOMBAÇA ${ }^{(1)}$
}

\author{
Thiago Lopes Rosado ${ }^{(2)}$, Ivoney Gontijo ${ }^{(3)}$, Marcelo Suzart de Almeida ${ }^{(3)}$ \& Felipe Vaz \\ Andrade $^{(4)}$
}

\section{RESUMO}

\begin{abstract}
$\mathrm{O}$ fornecimento de $\mathrm{N}$ tem sido importante meio para aumento da produtividade das gramíneas forrageiras tropicais no Brasil, pois, na maioria das áreas cultivadas, os teores desse nutriente no solo não atendem satisfatoriamente a necessidade das culturas. Avaliou-se o efeito da aplicação de diferentes fontes e doses de N sobre os atributos químicos de um Latossolo Amarelo e a produção do Panicum maximum cv. Mombaça. O experimento foi desenvolvido no Instituto Federal do Espírito Santo, campus Santa Teresa. O delineamento experimental utilizado foi em blocos casualizados, com três repetições, em esquema fatorial $3 \times 6$, sendo três fertilizantes nitrogenados (ureia, sulfato de amônio e nitrato de cálcio) e seis doses de $N(0,120$, $240,360,480$ e $600 \mathrm{~kg} \mathrm{ha}^{-1}$ ), totalizando 54 unidades experimentais. As doses de $\mathrm{N}$ foram aplicadas a cada 28 dias, sempre após o corte da forrageira, totalizando sete aplicações durante o período experimental de 196 dias. Após o término do experimento, foram coletadas, com o auxílio de um trado holandês, amostras de solo na profundidade de 0-20 e 20-40 cm, para avaliar o efeito da aplicação dos tratamentos sobre os atributos químicos do solo nas diferentes profundidades. Os resultados experimentais evidenciaram que o sulfato de amônio apresentou elevado potencial de acidificação do solo. As alterações provocadas no pH do solo resultaram em alterações nos teores de $\mathrm{Al}$ trocável, na acidez potencial e na disponibilidade de $\mathrm{P}$ no solo. A aplicação de elevadas doses de $\mathrm{N}$ na forma de sulfato de amônio e nitrato de cálcio promoveu a lixiviação de bases, especialmente do $\mathrm{K}$ para a profundidade de $20-40 \mathrm{~cm}$.
\end{abstract}

Termos de indexação: Panicum maximum, fertilizantes nitrogenados, acidez do solo, lixiviação de bases.

\footnotetext{
(1) Parte da Dissertação de Mestrado do primeiro autor, que será apresentada ao Programa de Pós Graduação em Agricultura Tropical, Centro Universitário Norte do Espírito Santo - CEUNES-UFES. Recebido para publicação em 3 de abril de 2013 e aprovado em 28 de janeiro de 2014.

(2) Mestrando em Agricultura Tropical, Centro Universitário Norte do Espírito Santo - CEUNES-UFES. Rodovia BR 101 norte km 60, Litorâneo. CEP 29932-540 São Mateus (ES). E-mail: thiagolr@ifes.edu.br

(3) Professor, CEUNES-UFES. E-mail: ivoneygontijo@ceunes.ufes.br, marceloalmeida@ceunes.ufes.br

(4) Professor, Centro de Ciências Agrárias da Universidade Federal do Espírito Santo. Rua Alto Universitário, s/n, Guararema. CEP 29500-000 Alegre (ES). E-mail: felipe.andrade@ufes.br
} 


\title{
SUMMARY: THE EFFECT OF SOURCES AND APPLICATION DOSES OF NITROGEN ON THE CHEMICAL PROPERTIES OF AN OXISOL CULTIVATED WITH GUINEA GRASS
}

\begin{abstract}
Nitrogen supplementation has been an important means for increasing yield in tropical gramineous forage plants in Brazil because, in most growing areas, the levels of this nutrient in the soil do not adequately meet crop needs. We assessed the effect of different sources and application rates of $N$ on the chemical properties of an Oxisol (Latossolo Amarelo) and the production of Panicum maximum $c v$. Mombaça. The experiment was carried out at the Instituto Federal do Espírito Santo (State of Espirito Santo, Brazil), Santa Teresa campus. A randomized block experimental design with three replications was used in a $3 \times 6$ factorial arrangement, with three $N$ fertilizers (urea, ammonium sulfate, and calcium nitrate) and six $N$ doses $(0,120$, 240, 360, 480, and $\left.600 \mathrm{~kg} \mathrm{ha}^{-1}\right)$, for a total of 54 experimental units. The $\mathrm{N}$ was applied every 28 days, always after cutting the forage, for a total of seven applications over the 196-day experimental period. At the end of the experiment, soil samples were collected at the depth of 0-20 and 20-40 cm with the aid of a Dutch auger to evaluate the effect of the application rate on the chemical properties of the soil at the different depths. The experimental results showed high potential for soil acidification from ammonium sulfate. The changes brought about in soil $\mathrm{pH}$ resulted in changes in exchangeable Al content, in potential acidity, and in P availability in the soil. The application of high rates of $N$ in the form of ammonium sulfate and calcium nitrate led to leaching of bases, especially $K$ at the depth of $20-40 \mathrm{~cm}$.
\end{abstract}

Index terms: Panicum maximum, nitrogen fertilizers, soil acidity, leaching of bases.

\section{INTRODUÇÃO}

O conceito de manejo de pastagem tem mudado nos últimos anos, fazendo com que as pesquisas sejam voltadas principalmente para a busca de variedades mais responsivas à adubação.

No Brasil, o Panicum maximum é uma das forrageiras mais utilizadas em sistema de produção animal, pela boa adaptação climática e elevada produtividade (Gomes et al., 2011). Dentre as espécies cultivadas, destaca-se o Panicum maximum cv. Mombaça. Segundo Mingotte et al. (2011), trata-se de uma cultivar que apresenta forragem de boa qualidade, possuindo grande importância para a produção de bovinos nas regiões de clima tropical e subtropical.

A adubação nitrogenada tem sido utilizada como importante estratégia para o incremento da produção de forragem. Em áreas manejadas intensivamente, o fornecimento de $\mathrm{N}$ tem grande importância para a manutenção de níveis elevados de produção. Isso se justifica, pois o $\mathrm{N}$ é, ao lado do $\mathrm{K}$, o nutriente mais extraído em pastagem de Panicum maximum (Freitas et al., 2011). De acordo com Freitas et al. (2005), para manter níveis elevados de produção, o capim-mombaça pode extrair, anualmente, quantidade superior a $260 \mathrm{~kg} \mathrm{ha}^{-1}$ de N.

No Brasil, os fertilizantes nitrogenados mais comercializados e aplicados em pastagens são a ureia e o sulfato de amônio, representando mais de 90 \% do mercado, sendo a ureia a fonte mais utilizada (Martha Júnior et al., 2004). O uso dessas fontes apresenta vantagens e desvantagens. A ureia destaca-se pelo menor custo por $\mathrm{kg}$ de N. Porém, do ponto de vista agronômico, evidencia limitações nas aplicações em superfície, em razão das perdas de $\mathrm{N}$ por volatilização. Por sua vez, o sulfato de amônio demonstra menores perdas de N por volatilização quando aplicado em solos ácidos, além de ser fonte de $\mathrm{S}$, embora apresente maior custo por kg de N (Teixeira Filho et al., 2010).

Outros fertilizantes nitrogenados também são utilizados em pastagens, destacando-se entre esses o nitrato de cálcio. De acordo com Cantarella (1998), por fornecer $\mathrm{N}$ na forma nítrica, essa fonte não está sujeita às perdas por volatilização da $\mathrm{NH}_{3}$ em solos ácidos.

Segundo Costa et al. (2008b), há variações no comportamento dos atributos químicos de um solo que recebe a aplicação de diferentes fontes de N. Isso ocorre em razão das características de cada fertilizante, principalmente no que se refere à forma (nítrica, amoniacal ou amídica) que o $\mathrm{N}$ é fornecido.

Objetivou-se neste trabalho avaliar o efeito da aplicação de fontes e doses de $\mathrm{N}$ nos atributos químicos de um Latossolo Amarelo e na produção do capimmombaça (Panicum maximum Jacq.).

\section{MATERIAL E MÉTODOS}

O experimento foi realizado no período de $1^{\circ}$ de outubro de 2011 a 14 de abril de 2012, no Setor de Animais de Médio Porte do Instituto Federal do Espírito Santo, campus Santa Teresa, situado entre as coordenadas $19^{\circ} 48^{\prime} 36^{\prime \prime}$ de latitude sul e $40^{\circ} 40^{\prime} 48^{\prime \prime}$ de longitude oeste de Greenwich e altitude média de 150 m, no município de Santa Teresa, ES. O clima da região é temperado úmido com inverno seco e verão quente, Cwa, segundo a classificação de Köppen. 
A área utilizada de pastagem foi de $1.200 \mathrm{~m}^{2}$, com parcelas de $6 \mathrm{~m}^{2}$, totalizando $324 \mathrm{~m}^{2}$ de área útil. A pastagem de capim-mombaça encontrava-se estabelecida há mais de quatro anos, com elevada produção e manejo da fertilidade do solo realizado, segundo recomendações técnicas de Prezotti et al. (2007), para pastagensirrigadas de elevada exigência nutricional.

O solo foi classificado como Latossolo Amarelo eutrófico (LAe), textura argilosa (Embrapa, 1999), apresentando 343, 170 e $487 \mathrm{~g} \mathrm{~kg}^{-1}$ de areia, silte e argila, respectivamente. Quatro meses antes do início do experimento, foi feita análise química do solo. A partir dos resultados, realizou-se a calagem, 110 dias antes do início do experimento, com a aplicação de $1.000 \mathrm{~kg} \mathrm{ha}^{-1}$ de calcário dolomítico. A adubação (exceto o fornecimento de $\mathrm{N}$ ) foi realizada 90 dias após a calagem, de acordo com o Manual de Recomendação de Calagem e Adubação para o Estado do Espírito Santo (Prezotti et al., 2007), considerando como cultura o capim-mombaça. Aplicaram-se, na área experimental, $463 \mathrm{~kg} \mathrm{ha}^{-1}$ de superfosfato triplo, $434 \mathrm{~kg} \mathrm{ha}^{-1}$ de cloreto de potássio e $60 \mathrm{~kg} \mathrm{ha}^{-1}$ de FTE BR 10. A calagem e as adubações mencionadas foram realizadas a lanço, em superfície, sem incorporação. Imediatamente antes do início do experimento, fez-se nova amostragem do solo da área experimental, nas profundidades de 0-20 e 20-40 cm (Quadro 1).

$\mathrm{O}$ delineamento experimental utilizado foi em blocos casualizados. Adotou-se o esquema fatorial $3 \times 6$, sendo três fertilizantes nitrogenados (ureia, sulfato de amônio e nitrato de cálcio) e seis doses de $\mathrm{N}$ $\left(0,120,240,360,480\right.$ e $\left.600 \mathrm{~kg} \mathrm{ha}^{-1}\right)$, com três repetições, totalizando 54 unidades experimentais.

As doses de $\mathrm{N}$ estabelecidas foram igualmente divididas e aplicadas a cada 28 dias, sempre após o corte do capim-mombaça, totalizando sete aplicações durante o período experimental de 196 dias.

As parcelas de $3 \times 2 \mathrm{~m}$ cada foram demarcadas, com bordadura de $1 \mathrm{~m}$. Realizou-se em seguida o corte de uniformização em toda a área, com o auxílio de uma roçadora, modelo Stihl FS $220^{\circledR}$. Posteriormente, procedeu-se à aplicação dos tratamentos. Os tratamentos (fontes e doses de $\mathrm{N}$ ) foram dissolvidos em $10 \mathrm{~L}$ de água e aplicados nas parcelas com o auxílio de um regador, visando melhor distribuição dos fertilizantes nitrogenados.

Imediatamente após cada aplicação das doses e fontes nitrogenadas, foi aplicada em toda área experimental uma lâmina de irrigação de $8 \mathrm{~mm}$, utilizando sistema de irrigação por aspersão, com eficiência de aplicação de $74 \%$.

Durante todo o período experimental, sempre que a precipitação pluvial foi insuficiente, a pastagem foi irrigada, sendo a lâmina aplicada calculada em razão da evapotranspiração da cultura (ETc). As informações meteorológicas utilizadas para os cálculos da ETc foram fornecidas por uma estação climatológica automática, localizada a $550 \mathrm{~m}$ da área experimental. $\mathrm{Na}$ figura 1, são apresentadas algumas variáveis climáticas observadas no período experimental.

A produção de forragem referente aos três primeiros cortes não foi avaliada. Como antes da calagem, a pastagem era manejada intensivamente e recebia elevadas doses de N, utilizou-se esse período, buscando reduzir os teores de $\mathrm{N}$ do solo, de forma que a resposta do capim-mombaça ocorresse por causa dos tratamentos aplicados e não do estoque de $\mathrm{N}$ que o solo dispunha. Dessa forma, os resultados apresentados para produção de matéria seca referemse aos últimos quatro cortes.

A coleta da forrageira para cada corte foi realizada com auxílio de um quadrado de ferro de 0,50×0,50 m $\left(0,25 \mathrm{~m}^{2}\right)$ e cortada com tesoura de aço a $30 \mathrm{~cm}$ da superfície do solo, simulando a altura ideal de rebaixamento dessa forrageira (Silva et al., 2009). Após cada corte de avaliação, foi realizado o corte de uniformização de toda a área experimental, na mesma altura de corte das plantas avaliadas, sendo retirado da área o material vegetal resultante da uniformização.

O material coletado em cada corte, em $0,25 \mathrm{~m}^{2}$, foi acondicionado em um balde plástico, identificado e imediatamente pesado, obtendo-se o peso da massa fresca da gramínea. Em seguida, uma amostra

Quadro 1. Caracterização química do solo da área experimental, nas profundidades de 0-20 e 20-40 cm, antes e após a calagem e adubação do solo

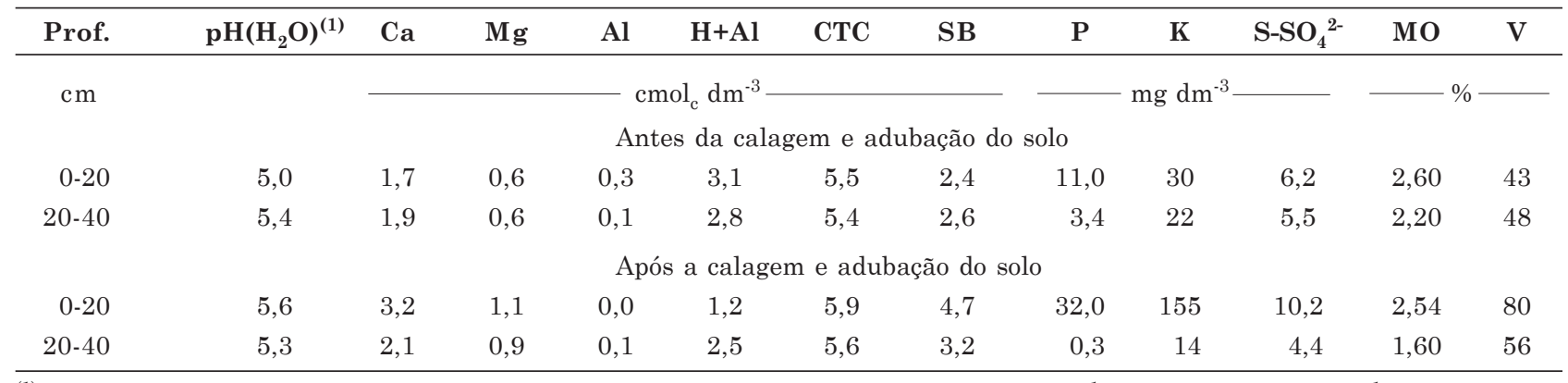

(1) $\mathrm{pH}\left(\mathrm{H}_{2} \mathrm{O}\right)$ : relação solo:solução - 1:2,5; P e K: extraídos por Mehlich-1 (HCI 0,05 mol L-1 $+\mathrm{H}_{2} \mathrm{SO}_{4} 0,025 \mathrm{~mol} \mathrm{~L}{ }^{-1}$ ); Ca, $\mathrm{Mg}$ e Al: extraídos por KCl 1,0 mol L-1; $\mathrm{H}+\mathrm{Al}$ : extraídos por acetato de cálcio $0,5 \mathrm{~mol} \mathrm{~L}^{-1}$; CTC: capacidade de troca de cátions a $\mathrm{pH} 7,0$; $\mathrm{SB}$ : soma de bases; ${\mathrm{S}-\mathrm{SO}_{4}}^{2-}$ : extraído por fosfato de cálcio $0,01 \mathrm{~mol} \mathrm{~L}^{-1}$; $\mathrm{MO}$ : matéria orgânica; e V: saturação por bases. 
representativa da forragem de aproximadamente $400 \mathrm{~g}$ foi retirada do material coletado, acondicionada em saco de papel, identificada e em seguida levada à estufa com circulação de ar, onde a temperatura foi mantida entre 60 e $65^{\circ} \mathrm{C}$, até atingir massa constante, para determinação da matéria pré-seca. Após a secagem, as amostras foram moídas em moinho do tipo Willey, com peneira de $1 \mathrm{~mm}$ e acondicionadas em sacos de polietileno. Posteriormente, o material moído foi novamente levado para estufa, para remoção da umidade residual. A produção de matéria seca por hectare foi determinada utilizando a massa fresca do material coletado na área de $0,25 \mathrm{~m}^{2}$, e a massa de matéria seca, obtido após o processamento da amostra, pela fórmula: $\mathrm{PMS}=[\% \mathrm{MS} \mathrm{x}(\mathrm{MF} \times 40.000)] / 100, \mathrm{em}$ que PMS: Produção de Matéria Seca, em kg ha-1; \% MS: Percentual de Matéria Seca da amostra após o processamento; MF: Matéria Fresca, coletada em $0,25 \mathrm{~m}^{2}$; e 40.000: fator utilizado para conversão da produção em hectare.

Ao final do período experimental, foram coletadas, com o auxílio de um trado holandês, amostras de solo nas profundidades de 0-20 e 20-40 cm, para avaliar os atributos químicos do solo nas diferentes profundidades. Em cada parcela de $6 \mathrm{~m}^{2}$, coletaramse quatro amostras simples para cada profundidade avaliada, que foram homogeneizadas para obtenção de uma amostra composta. Essa, posteriormente, foi seca ao ar, destorroada e passada em peneira de 2 $\mathrm{mm}$ para obtenção de terra fina seca ao ar (TFSA); em seguida, foi encaminhada para o laboratório para a realização das seguintes análises químicas: $\mathrm{pH}$ $\left(\mathrm{H}_{2} \mathrm{O}\right), \mathrm{Ca}, \mathrm{Mg}$ e Al trocáveis (extrator $\mathrm{KCl} 1,0 \mathrm{~mol} \mathrm{~L}^{-1}$ ), $\mathrm{P} \mathrm{e} \mathrm{K}$ (extrator Mehlich-1, HCI 0,05 $\mathrm{mol} \mathrm{L}^{-1}+\mathrm{H}_{2} \mathrm{SO}_{4}$ $0,025 \mathrm{~mol} \mathrm{~L}^{-1}$ ), acidez potencial (extrator acetato de cálcio $0,5 \mathrm{~mol} \mathrm{~L}^{-1}$ ) e $\mathrm{S}$ (extrator fosfato de cálcio $0,01 \mathrm{~mol} \mathrm{~L}^{-1}$ ).

Os dados foram submetidos à análise de variância e, em razão da significância para as variáveis, foram ajustadas equações de regressão. Adotou-se o nível de

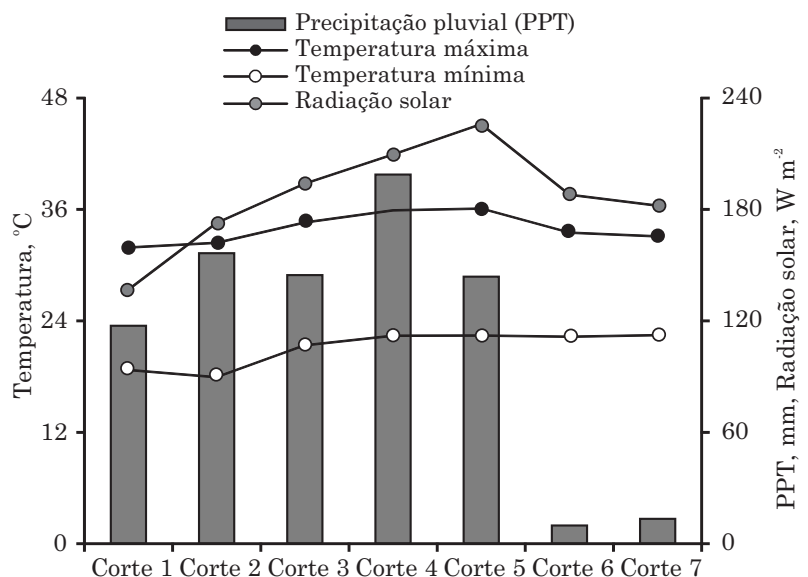

Figura 1. Valores das variáveis climáticas observadas durante o período experimental (outubro/2011 a abril/2012). significância de $5 \%$ em todos os testes estatísticos, utilizando o programa SAS (1993).

\section{RESULTADOS E DISCUSSÃO}

A produção acumulada de matéria seca (PMS) do capim-mombaça em razão dos tratamentos aplicados é apresentada na figura 2 . Observou-se que o modelo de ajuste linear foi o que melhor representou o comportamento dos dados, evidenciando para as diferentes fontes avaliadas aumento da produção com até $600 \mathrm{~kg} \mathrm{ha}^{-1} \mathrm{de} \mathrm{N}$. Quando submetido à dose máxima de N, a PMS do capim-mombaça foi 49 , 71 e $102 \%$ superior ao controle, para as fontes ureia, sulfato de amônio e nitrato de cálcio, respectivamente. De acordo com Lemaire \& Chapman (1996), o N tem influência marcante nos componentes estruturais das forrageiras, destacando-se o comprimento final das folhas e o número de folhas vivas por perfilho, que, em última análise, determinam o índice de área foliar do pasto e sua produção.

Para doses maiores que $273 \mathrm{~kg} \mathrm{ha}^{-1} \mathrm{de} \mathrm{N}$, o nitrato de cálcio apresentou resultados superiores em PMS, quando comparado com o sulfato de amônio e a ureia. As maiores respostas em produção para gramíneas forrageiras utilizando $\mathrm{N}$ nítrico foram discutidas por diversos autores, como Whitehead (1995) e Corrêa et al. (2007). A dinâmica do nitrato no solo e suas características químicas reduzem significativamente as perdas com sua aplicação, justificando os resultados apresentados.

Comparando apenas as fontes ureia e sulfato de amônio, observou-se que para a dose máxima de N, a produção obtida com a aplicação do sulfato de amônio foi $15 \%$ superior àquela observada com o uso da ureia. Resultados semelhantes foram obtidos por Costa et al. (2010), em que observaram, em trabalhos com capim-marandu, redução da PMS na ordem de $18 \%$

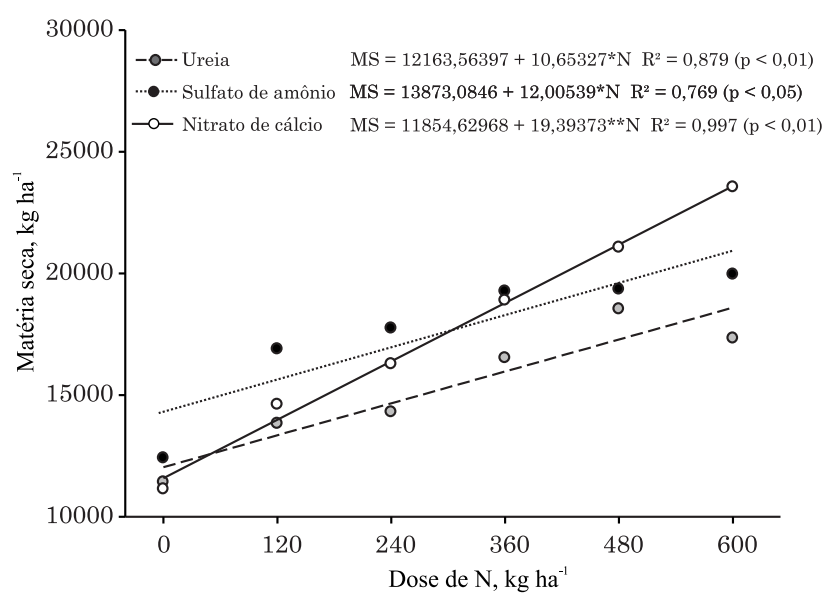

Figura 2. Produção acumulada de matéria seca do capim-mombaçaem resposta à aplicação de fontes e doses de nitrogênio.* e **: nível de significância de 5 e $1 \%$, respectivamente. 
para a dose máxima de $\mathrm{N}$ (300 $\left.\mathrm{kg} \mathrm{ha}^{-1}\right)$, quando utilizou-se ureia como fonte, comparado ao sulfato de amônio.

$\mathrm{Na}$ figura 3 , é apresentada a variação do $\mathrm{pH}$ do solo para as profundidades de 0-20 e $20-40 \mathrm{~cm}$, em razão da aplicação de fontes e doses de N. Observouse na figura 3a que o aumento das doses de $\mathrm{N}$, para as fontes ureia e sulfato de amônio, promoveu decréscimos lineares nos valores de $\mathrm{pH}$ do solo para a profundidade de $0-20 \mathrm{~cm}$. O sulfato de amônio gerou maior acidificação do solo em todas as doses aplicadas. De acordo com Tasca et al. (2011), a formação do amônio a partir da hidrólise da ureia produziu inicialmente aumento do $\mathrm{pH}$ do solo, em razão do consumo de íons $\mathrm{H}^{+}$. Porém, após a nitrificação do amônio, o pH decresceu para valores inferiores aos
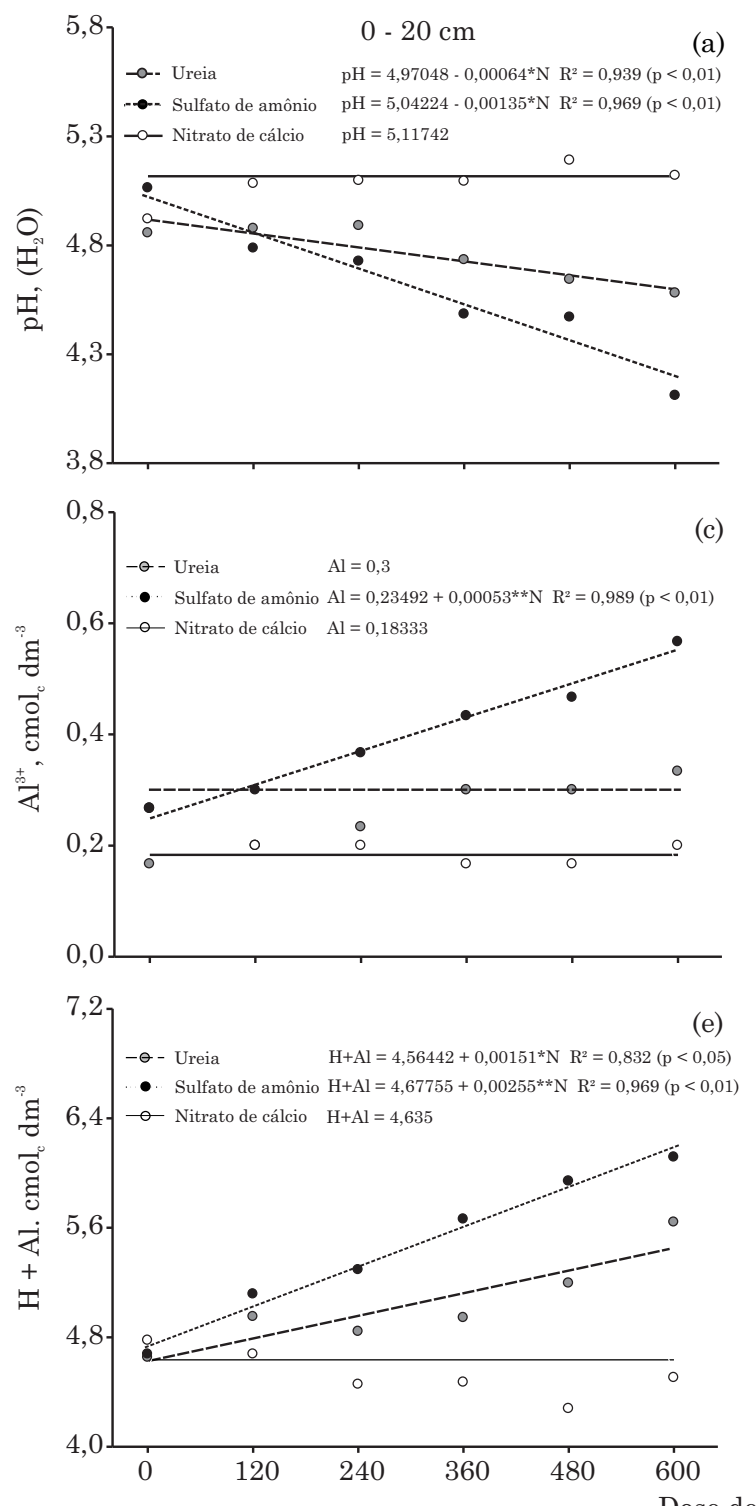

Dose de N, kg ha ${ }^{-1}$
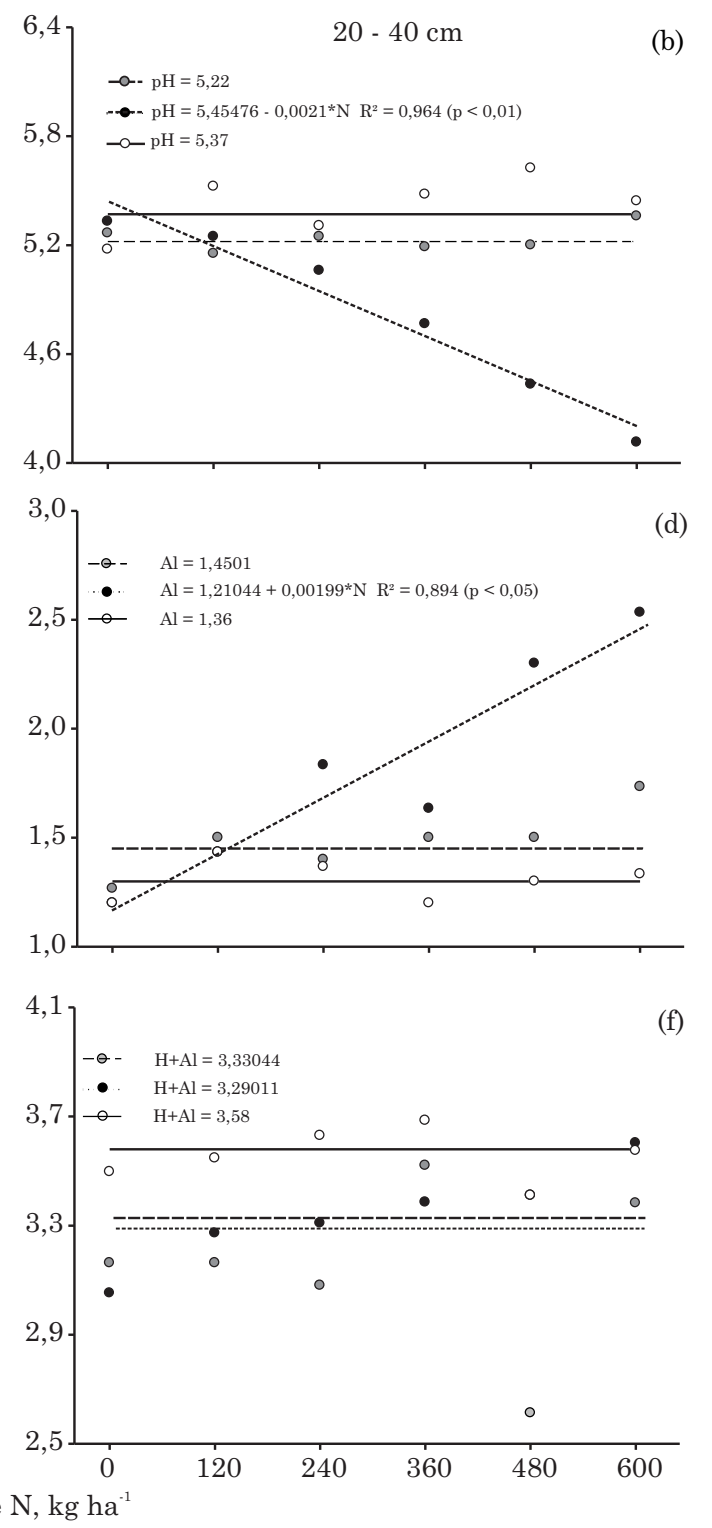

Figura 3. Valores de pH em água (a, b), de alumínio trocável(c, d) e de acidez potencial (H+Al)(e, f), nas profundidades de 0-20 e 20-40 cm do solocultivado com capim-mombaça, em resposta à aplicação de fontes e doses de nitrogênio.* $e^{* *}$ : nível de significância de 5 e 1 \%, respectivamente. 
um Latossolo Vermelho-Amarelo distrófico, cultivado com capim-xaraés, ao final do período experimental de nove meses, redução do $\mathrm{pH}$ do solo de 0,7 e 0,3 unidades, quando a pastagem foi submetida à aplicação de $400 \mathrm{~kg} \mathrm{ha}^{-1}$ de $\mathrm{N}$, utilizando as fontes sulfato de amônio e ureia, respectivamente.

Não apenas as características químicas dos fertilizantes utilizados, no que se refere à geração e consumo de íons $\mathrm{H}^{+}$, apresentadas anteriormente, justificaram as diferenças no comportamento observado no pH do solo. Costa et al. (2008b) apontaram outros fatores que podem contribuir para que o sulfato de amônio apresentasse maior potencial de acidificação do solo. Segundo esses autores, no solo, o sulfato de amônio dissocia-se, atuando como carreador de cátions para as camadas subsuperficiais. Dessa forma, a remoção de cátions das camadas superficiais promove aumento da acidificação do solo. Além disso, a volatilização da $\mathrm{NH}_{3}$ proveniente da ureia aplicada em superfície reduziu as quantidades de $\mathrm{NH}_{4}^{+}$nitrificado e, consequentemente a formação de $\mathrm{H}^{+}$. Porém, pelo manejo adotado na aplicação dos fertilizantes nitrogenados, bem como a irrigação realizada logo após a aplicação dos tratamentos, acreditou-se que as perdas de $\mathrm{N}$ por volatilização da $\mathrm{NH}_{3}$ tenham sido pouco expressivas.

Pôde-se observar ainda, analisando o quadro 1 e a figura $3 \mathrm{a}$, que, mesmo para o controle, o $\mathrm{pH}$ do solo sofreu redução de 0,7 unidade durante o período experimental. Reduções significativas nos valores de $\mathrm{pH}$, mesmo na ausência da aplicação de $\mathrm{N}$, foram observadas por diversos autores. Reis et al. (2011) observaram redução do $\mathrm{pH}$ na ordem de 0,45 unidade para a profundidade de $0-20 \mathrm{~cm}$, após 12 meses de cultivo de Brachiaria brizantha, enquanto Delbem et al. (2011) verificaram, após 11 meses de cultivo do capim-braquiária, redução do $\mathrm{pH}$ na profundidade de $10-20 \mathrm{~cm}$ de 0,4 unidade. De acordo com Malavolta (2006), a absorção de cátions pelas plantas, com posterior extrusão de íons $\mathrm{H}^{+}$, a lixiviação das bases do solo, a exsudação de ácidos orgânicos pelas raízes das plantas, além da mineralização da matéria orgânica do solo, podem promover a acidificação do solo, justificando os resultados apresentados.

Quando o $\mathrm{N}$ foi fornecido na forma de nitrato de cálcio, não ocorreram alterações no $\mathrm{pH}$ do solo em função das doses aplicadas nas diferentes profundidades avaliadas. De acordo com Malavolta (1981), o nitrato de cálcio é um fertilizante que contém $\mathrm{N}$ na forma nítrica, não passando por transformações no solo. Sendo assim, sua aplicação não promove alterações no $\mathrm{pH}$ do solo, concordando com os resultados deste trabalho.

Para a profundidade de $20-40 \mathrm{~cm}$ (Figura 3b), pôdese observar que, quando se utilizou o sulfato de amônio como fonte de N, ocorreram reduções nos valores de $\mathrm{pH}$ com o aumento da dose de $\mathrm{N}$ aplicada. Esse comportamento não foi observado com a aplicação de ureia, para a qual não foi obtido ajuste de equação com coeficiente significativo. Souza et al. (2007) relataram que as variações de $\mathrm{pH}$ estão relacionadas ao poder tampão hidrogeniônico do solo, que, de acordo com Abreu Junior et al. (2001), é dependente do teor e tipo de mineral que compõem a fração argila, dos teores de matéria orgânica, que juntos determinam a Capacidade de Troca de Cátions (CTC) do solo. Dessa forma, os atributos físico-químicos do solo, utilizados neste experimento, provavelmente explicam esses resultados.

Os valores de $\mathrm{Al}$ trocável e da acidez potencial (H + Al) no solo também sofreram alterações, em razão dos tratamentos aplicados. Comparando a figura $3 \mathrm{a}, \mathrm{b}, \mathrm{c}, \mathrm{d}$, quando o $\mathrm{N}$ foi fornecido na forma de sulfato de amônio, pôde-se observar a existência de uma relação inversa muito estreita entre $\mathrm{pH}$ do solo e teores de $\mathrm{Al}$; a redução do $\mathrm{pH}$ do solo provocado pelas doses crescentes de $\mathrm{N}$ promoveram aumento nos valores para esse atributo. Para os valores de $\mathrm{H}+\mathrm{Al}$, observou-se também essa relação, quando se comparam a figura $3 \mathrm{a}$,e.

Esse comportamento para os teores de $\mathrm{Al} \mathrm{e} \mathrm{H}+\mathrm{Al}$, resultante da adição de fertilizantes nitrogenados em solos sob gramíneas, foram relatados por outros autores como Costa et al. (2008) e Vale (2009). Para os teores de $\mathrm{Al}$, nas diferentes profundidades avaliadas (Figura 3c,d), não se observou efeito da adubação nitrogenada quando o $\mathrm{N}$ foi fornecido na forma de ureia e nitrato de cálcio. Para o sulfato de amônio, o aumento das doses de $\mathrm{N}$ promoveu aumento nos teores de $\mathrm{Al}$, em virtude da maior acidificação do solo provocada por essa fonte.

De acordo com Souza et al. (2007), a acidez do solo controla a reação de dissolução do $\mathrm{Al}$, sendo mínima sua solubilidade para valores de $\mathrm{pH}$ em $\mathrm{H}_{2} \mathrm{O}$ acima de 5,5 . De acordo com os resultados apresentados, notouse que a adubação com sulfato de amônio apresentou maior potencial de acidificação do solo e elevação dos teores de $\mathrm{Al} \mathrm{e} \mathrm{H}+\mathrm{Al}$, e esse comportamento se estendeu para a profundidade de $20-40 \mathrm{~cm}$, fato não observado com o uso de ureia.

Os teores de Ca no solo também foram influenciados pelos tratamentos aplicados. Na figura 4a, observouse que houve aumento nos teores desse elemento, quando se utilizou o nitrato de cálcio como fonte de N. O fertilizante utilizado apresentou em sua composição $19 \%$ de Ca. Assim, foram fornecidos 147, 294, 441, 588 e $735 \mathrm{~kg} \mathrm{ha}^{-1}$ de $\mathrm{Ca}$, para os tratamentos que receberam 120, 240, 360, 480 e $600 \mathrm{~kg} \mathrm{ha}^{-1}$ de N, respectivamente. Para as demais fontes, não houve influência das doses de $\mathrm{N}$ sobre os teores desse nutriente no solo. Observou-se ainda que o incremento nos teores de Ca, em razão da aplicação de nitrato de cálcio, ficou restrito à profundidade de $0-20 \mathrm{~cm}$ (Figura 4b), por causa da elevada energia de ligação existente entre esse cátion e os coloides do solo, reduzindo sua movimentação no perfil desse, fato que será melhor discutido posteriormente. 

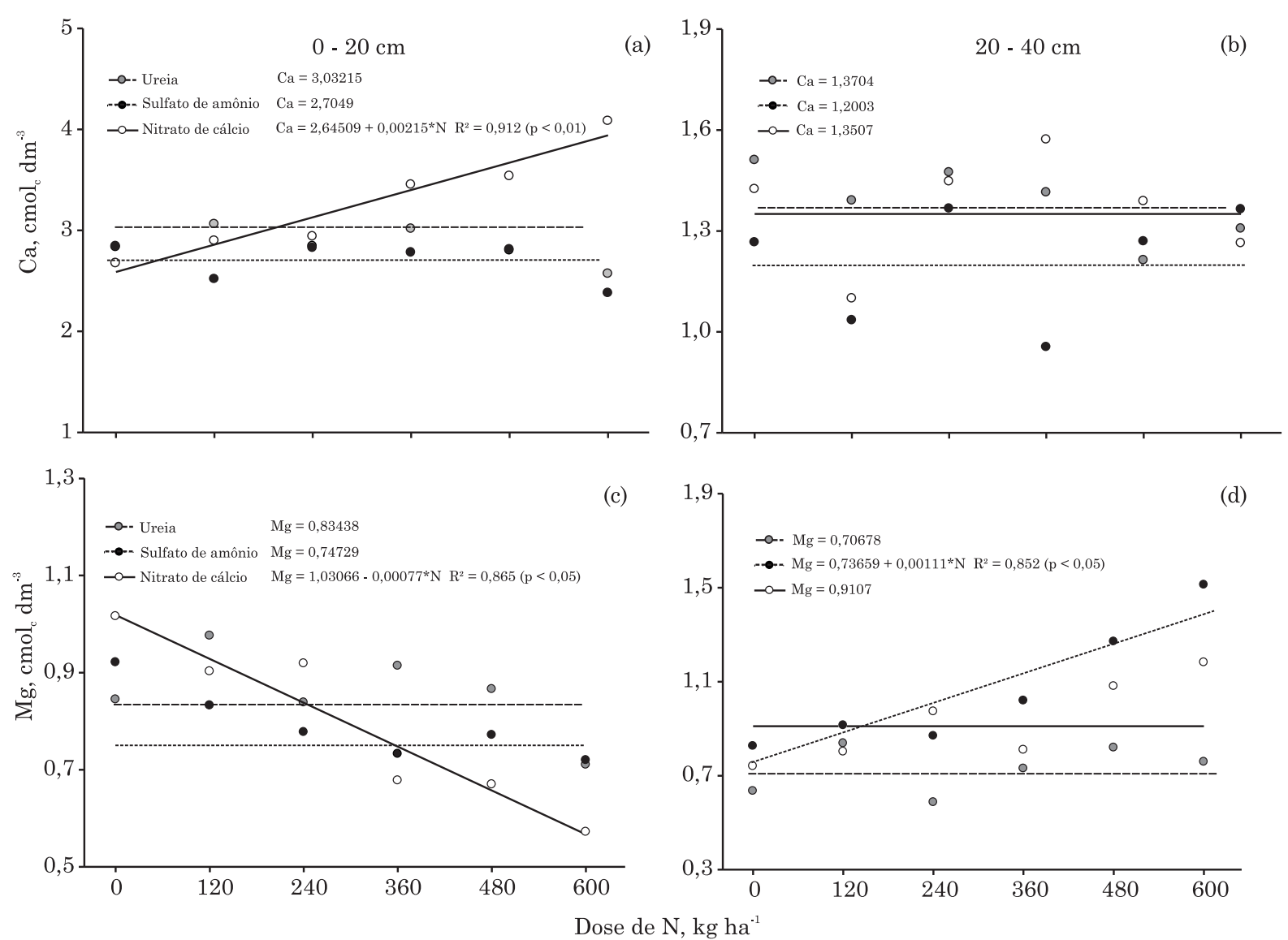

Figura 4. Teores de cálcio (a, b) e de magnésio (c, d), nas profundidades de 0-20 e 20-40 cm do solo cultivado com capim-mombaça, em resposta à aplicação de fontes e doses de nitrogênio.

$\mathrm{O}$ comportamento dos teores de $\mathrm{S}-\mathrm{SO}_{4}{ }^{2-}$, para as profundidades de 0-20 e 20-40 cm do solo, em razão dos tratamentos aplicados, é apresentado na figura 5a,b. Pôde-se observar na profundidade de 0-20 cm redução gradual dos teores desse nutriente no solo com o aumento das doses de $\mathrm{N}$, para as fontes ureia e nitrato de cálcio. Essa redução pode ser explicada pela maior absorção desse elemento pelo capim-mombaça nas maiores doses de N. Quando se utilizou o sulfato de amônio como fonte de $\mathrm{N}$, ocorreu elevação dos teores de $\mathrm{S}_{-} \mathrm{SO}_{4}{ }^{2-}$ no solo com o aumento da dose aplicada. Esse fertilizante apresenta em sua composição $24 \%$ de $\mathrm{S}_{-} \mathrm{SO}_{4}{ }^{2-}$, e para os tratamentos que receberam 120 , $240,360,480$ e $600 \mathrm{~kg} \mathrm{ha}^{-1}$ de N, houve adição de 144, 288, 432, 576 e $720 \mathrm{~kg} \mathrm{ha}{ }^{-1}$ de $\mathrm{S}_{-} \mathrm{SO}_{4}{ }^{2-}$ ao solo, explicando os resultados apresentados. O incremento nos teores de $\mathrm{S}_{-} \mathrm{SO}_{4}{ }^{2-}$, em razão da aplicação de sulfato de amônio, alcançou a profundidade de 20-40 cm, evidenciando sua mobilidade no solo, por meio da associação do $\mathrm{SO}_{4}^{2-}$ com os cátions $\mathrm{Mg}$ e K.

A aplicação de nitrato de cálcio promoveu redução nos teores de $\mathrm{Mg}$ e K, na profundidade de $0-20 \mathrm{~cm}$ do solo, como estão apresentadas nas figuras $4 \mathrm{c}$ e $5 \mathrm{c}$, respectivamente. Comportamento também observado com o uso de sulfato de amônio como fonte de $\mathrm{N}$, onde ocorreram reduções nos teores de $\mathrm{K}$ na profundidade de $0-20 \mathrm{~cm}$ do solo (Figura 5c). Esses resultados concordam com os obtidos por Sarmento et al. (2008), que observaram redução dos teores de $\mathrm{Mg}$ e $\mathrm{K}$ nas profundidades de 0-10 e 10-20 cm com o aumento das doses de $\mathrm{N}$ aplicadas, utilizando o nitrato de amônio como fonte de $\mathrm{N}$.

$\mathrm{O} \mathrm{NO}_{3}$ - fornecido pelo nitrato de cálcio, ou resultante da nitrificação do amônio, bem como o $\mathrm{SO}_{4}{ }^{2-}$, fornecido pelo sulfato de amônio, influenciou a dinâmica dos cátions $\mathrm{Mg}$ e $\mathrm{K}$ no solo. Trabalhos evidenciando a influência da adubação nitrogenada na movimentação de bases no perfil do solo foram iniciados por Pearson et al. (1962). De acordo com Foloni \& Rosolem (2006), a associação de cátions e ânions na solução do solo, com neutralização momentânea de cargas, pode intensificar a movimentação descendente de bases no perfil do solo.

Desta forma, para as condições impostas deste trabalho, os ânions $\mathrm{NO}_{3}$ - e $\mathrm{SO}_{4}^{2-}$ funcionaram como "carregadores" de Mge K, para a profundidade de 20-40 cm do solo. Assim, a redução dos teores desses nutrientes com o aumento das doses de $\mathrm{N}$ seria resultado não apenas da maior absorção pelas plantas, mas pela movimentação desses cátions para camadas subsuperficiais do solo. De acordo com Rosolem et al. (2003), os ânions $\mathrm{SO}_{4}{ }^{2-}$ e $\mathrm{NO}_{3}^{-}$provenientes da 

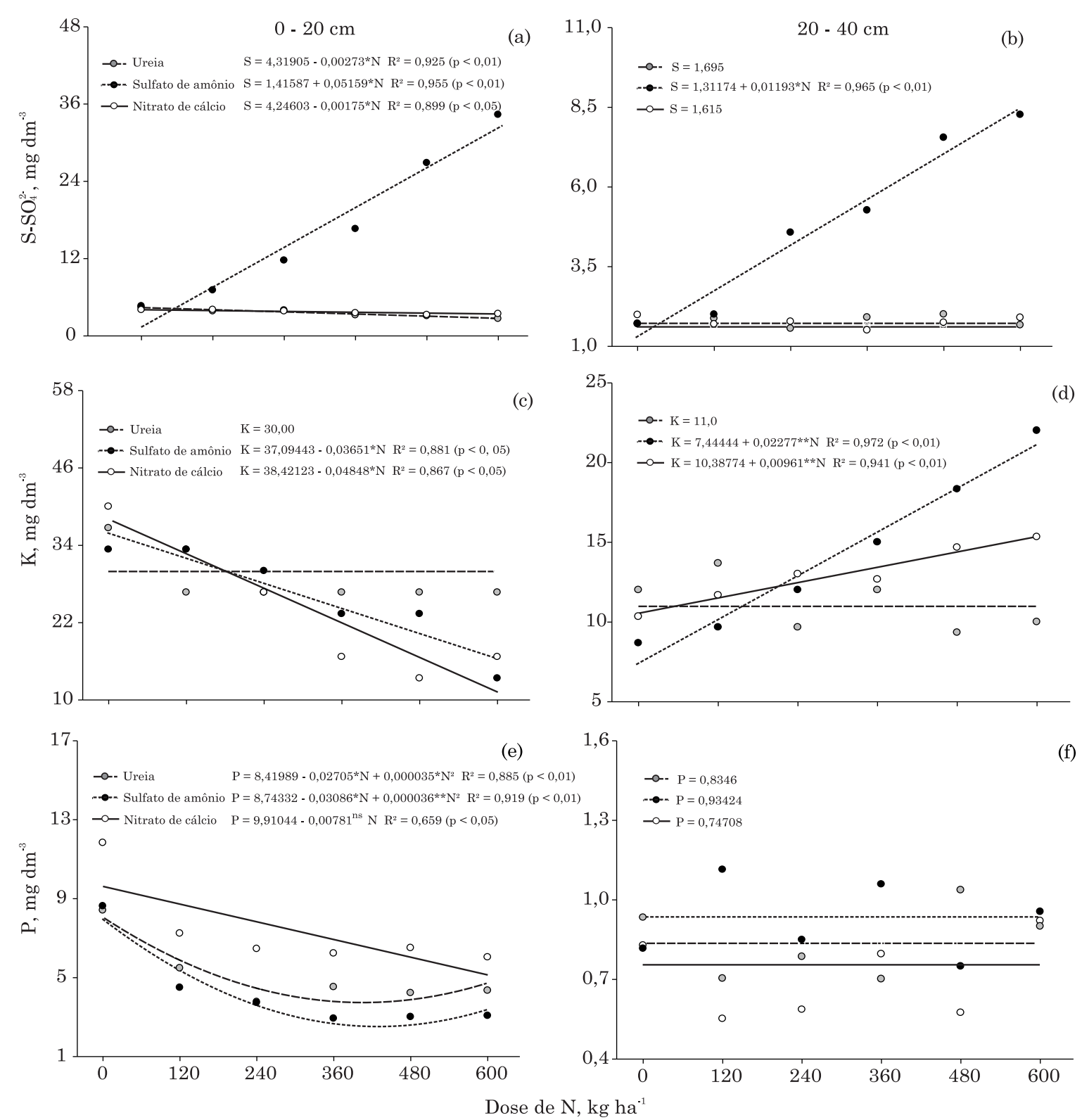

Figura 5. Teores de enxofre (a, b), de potássio (c, d) e de fósforo (e, f), nas profundidades de 0-20 e 20-40 cm do solo cultivado com capim-mombaça, em resposta à aplicação de fontes e doses de nitrogênio.

mineralização dos resíduos orgânicos e dos fertilizantes podem promover, em determinadas condições, a movimentação descendente dos cátions básicos $\left(\mathrm{Ca}^{2+}\right.$, $\mathrm{Mg}^{2+}$ e $\mathrm{K}^{+}$) no perfil, em virtude da associação iônica na solução do solo. Segundo Raij (1991), por causa da energia de ligação existente entre as bases trocáveis e os coloides do solo, há tendência que a lixiviação de $\mathrm{K}^{+}>\mathrm{Mg}^{2+}>\mathrm{Ca}^{2+}$. Essas informações concordaram com os resultados apresentados na figura $5 c, d$. Observou-se que a redução dos teores de K na profundidade $0-20 \mathrm{~cm}$ foi acompanhada pelo incremento desse nutriente na profundidade de 20-40 cm do solo, com o aumento das doses de sulfato de amônio e nitrato de cálcio aplicadas. Esse fato evidenciou claramente o potencial de movimentação de cátions, especialmente o $\mathrm{K}^{+}$, adsorvido com menor energia de ligação, quando o solo apresentou elevados teores de $\mathrm{NO}_{3}$ - e $\mathrm{SO}_{4}{ }^{2-}$, resultante da adubação nitrogenada.

Para o P, houve redução dos seus teores no solo para a profundidade de $0-20 \mathrm{~cm}$, com o aumento das doses de N, para as diferentes fontes avaliadas (Figura 5e). Esses resultados estão diretamente relacionados à maior PMS do capim-mombaça para as maiores doses de N (Figura 2), promovendo consequentemente maior extração desse nutriente pelas plantas. A associação entre maior produção de forragem e extração de $\mathrm{P}$ foi feita por Costa et al. (2008a) para o capim-xaraés, e Costa et al. (2009), para o capimmarandu, justificando os resultados apresentados. 
A redução dos teores de $\mathrm{P}$ no solo, com o aumento das doses de N, para as fontes sulfato de amônio e ureia, pode estar relacionado ainda à variação do $\mathrm{pH}$ do solo em razão dos tratamentos aplicados. Observouse, na figura 5e, que as maiores reduções nos teores de $\mathrm{P}$ foram observadas para o sulfato de amônio, seguido pela ureia. Sarmento et al. (2008), avaliando o efeito da adubação nitrogenada no Panicum maximum, atribuíram a redução dos teores de $\mathrm{P}$ no final do experimento à redução do $\mathrm{pH}$ do solo com consequente formação de fosfatos insolúveis de $\mathrm{Fe}$ e de Al. A explicação dada por esses autores pode ser utilizada para compreensão dos resultados deste trabalho, uma vez que, para o sulfato de amônio, que proporcionou maior acidificação do solo em razão das doses de $\mathrm{N}$, houve maior redução dos teores de $\mathrm{P}$, quando comparada com os da ureia e do nitrato de cálcio.

Mesmo na ausência da aplicação de N, houve redução significativa dos teores de $\mathrm{P}$ no solo, comparado com aqueles presentes antes do início do experimento. Esse fato pode ser atribuído à absorção desse nutriente pelas plantas durante o período experimental.

Notou-se que, com o uso do nitrato de cálcio, houve diminuição dos teores de $\mathrm{P}$ com o aumento das doses de $\mathrm{N}$ aplicadas. Como para essa fonte não houve alterações nos valores de $\mathrm{pH}$ e $\mathrm{Al}$ trocável do solo, em razão da aplicação de N, pode-se atribuir essa redução apenas à absorção desse nutriente pelo capimmombaça, por causa do aumento da PMS com a aplicação de $\mathrm{N}$, evidenciado na figura 2. Para a profundidade de $20-40 \mathrm{~cm}$ (Figura 5f), a aplicação de fontes e doses de $\mathrm{N}$ não promoveu alterações nos valores desse atributo no solo.

\section{CONCLUSÕES}

1. O fornecimento de $\mathrm{N}$ promoveu aumento linear na produção de matéria seca do capim-mombaça, onde os resultados, com a aplicação do nitrato de cálcio, foram superiores às demais fontes, nas doses mais elevadas de $\mathrm{N}$.

2. As fontes de $\mathrm{N}$ diferiram quanto aos efeitos provocados no $\mathrm{pH}$ do solo; o sulfato de amônio apresentou elevado potencial de acidificação, enquanto o nitrato de cálcio não promoveu alterações significativas do $\mathrm{pH}$, para as doses avaliadas.

3. Os valores de acidez potencial foram influenciados pelas fontes e doses de $\mathrm{N}$ aplicadas somente na profundidade de 0-20 cm do solo. Essa acidificação do solo provocada pela utilização da ureia e do sulfato de amônio como fonte de $\mathrm{N}$ promoveu reduções na disponibilidade de $\mathrm{P}$ às plantas.

4. A aplicação de elevadas doses de N, na forma de sulfato de amônio e nitrato de cálcio, gerou lixiviação de bases, especialmente o K, para a profundidade de $20-40 \mathrm{~cm}$ do solo.

\section{AGRADECIMENTOS}

Ao Instituto Federal do Espírito Santo, campus Santa Teresa; e ao Centro Universitário Norte do Espírito Santo, pela estrutura cedida para o desenvolvimento deste projeto.

\section{LITERATURA CITADA}

ABREU JUNIOR, C.H.; MURAOKA, T. \& OLIVEIRA, F.C. Cátions trocáveis, capacidade de troca de cátions e saturação por bases em solos brasileiros adubados com composto de lixo urbano. Sci. Agric., 58:813-824, 2001.

CANTARELLA, H. Adubação nitrogenada em sistema de cana crua. STAB, 16:21-22, 1998.

CORREAA, L.A.; CANTARELlA, H.; PRIMAVESI, A.C.; PRIMAVESI, O.; FREITAS, A.R. \& SILVA, A.G. Efeito de fontes e doses de nitrogênio na produção e qualidade da forragem de capim coastcross. R. Bras. Zootec., 36:763$772,2007$.

COSTA, K.A.P.; FAQUIN, V. \& OLIVEIRA, I.P. Doses e fontes de nitrogênio na recuperação de pastagens do capimmarandu. Arq. Bras. Med. Vet. Zootec., 62:192-199, 2010.

COSTA, K.A.P.; FAQUIN, V.; OLIVEIRA, I.P.; SEVERIANO, E.C.; SIMON, G.A. \& CARRIJO, M.S. Extração de nutrientes do capim-marandu sob doses e fontes de nitrogênio. R. Bras. Saúde Prod. Anim., 10:801-812, 2009.

COSTA, K.A.P.; ARAUJO, J.L.; FAQUIN, V.; OLIVEIRA, I.P.; FIGUEIREDO, F.C. \& GOMESI, K.W. Extração de macronutrientes pela fitomassa do capim-xaraés em função de doses de nitrogênio e potássio. Ci. Rural, 38:1162-1166, 2008a.

COSTA, K.A.P.; FAQUIN, V.; OLIVEIRA, I.P.; RODRIGUES, C. \& SEVERIANO, E.C. Doses e fontes de nitrogênio em pastagem de capim-marandu. I - Alterações nas características químicas do solo. R. Bras. Ci. Solo, 32:5911599, 2008b.

CROCIOLLI, C.A. Doses e fontes de fertilizantes nitrogenados e seus efeitos nos atributos químicos do solo, produção e estado nutricional da Brachiaria brizantha cv. Xaraés. Araçatuba, Universidade Estadual Paulista "Júlio de Mesquita Filho”, 2008. 70p. (Dissertação de Mestrado)

DELBEM, F.C.; SCABORA, M.H.; SOARES FILHO, C.V.; HEINRICHS, R.; CROCIOLLI, C.A. \& CASSIOLATO, A.M.R. Fontes e doses de adubação nitrogenada na atividade microbiana e fertilidade do solo cultivado com Brachiaria brizantha. Acta Sci. Agron., 33:361-367, 2011.

EMPRESA BRASILEIRA DE PESQUISA AGROPECUÁRIA EMBRAPA. Sistema brasileiro de classificação de solos. Rio de Janeiro, Embrapa Solos, 1999. 412p. 
FOLONI, J.S.S. \& ROSOLEM, C.A. Efeito da calagem e sulfato de amônio no algodão. I - Transporte de cátions e ânions no solo. R. Bras. Ci. Solo, 30:425-432, 2006.

FREITAS, K.R.; ROSA, B.; NASCIMENTO, J.L.; BORGES, R.T.; BARBOSA, M.M. \& SANTOS, D.C. Composição química do capim-mombaça (Panicum maximum jacq.) submetido à adubação orgânica e mineral. Ci. Anim. Bras.,12:407-414, 2011.

FREITAS, K.R.; ROSA, B.; RUGGIERO, J.A.; NASCIMENTO, J.L.; HEINEMAM, A.B.; FERREIRA, P.H. \& MACEDO, R. Avaliação do capim-mombaça (Panicum maximum Jacq.) submetido a diferentes doses de nitrogênio. Acta Sci. Agron., 27:83-89, 2005.

GOMES, R.A.; LEMPP, B.; JANK, L.; CARPEJANI, G.C. \& MORAIS, M.G. Características anatômicas e morfofisiológicas de lâminas foliares de genótipos de Panicum maximum. Pesq. Agropec. Bras., 46:205-211, 2011.

LEMAIRE, G. \& CHAPMAN, D.F. Tissue flows in grazed plant communities. In: HODGSON, J. \& ILLIUS, A.W., eds. The ecology and management of grazing systems. Oxon, CAB International, 1996. p.3-36.

MALAVOLTA, E. Manual de nutrição de plantas. São Paulo, Ceres, 2006. 638p.

MALAVOLTA, E. Manual de química agrícola: adubos e adubação. 3.ed. São Paulo, Ceres, 1981. 596p.

MARTHA JÚNIOR, G.B.; CORSI, M.; TRIVELIN, P.C.O.; VILELA, L.; PINTO, T.L.F.; TEIXEIRA, G.M.; MANZONI, C.S. \& BARIONI, L.G. Perdas de amônia por volatilização em pastagem de capim-tanzânia adubada com ureia no verão. R. Bras. Zootec., 33:2240-2247, 2004.

MINGOTTE, F.L.C.; SANTOS, C.L.R.; PRADO, R.M.; FLORES, R.A.; TOGORO, A.H.; SILVA, J.A.S.; POLITI, L.S.; PINTO, A.S. \& AQUINO, D.S. Manganês na nutrição e na produção de massa seca do capim-mombaça. Biosci. J., 27:879-887, 2011.

PEARSON, R.W.; ABRUNA, F. \& VICENTE-CHANDLER, J. Effect of lime and nitrogen applications on downward movement of calcium and magnesium in two humid tropical soils of Puerto Rico. Soil Sci., 93:77-82, 1962.

PREZOTTI, L.C.; GOMES, J.A.; DADALTO, G.G. \& OLIVEIRA, J.A. Manual de recomendação de calagem e adubação para o Estado do Espírito Santo. $5^{\circ}$ aproximação. Vitória, SEEA/Incaper/Cedagro, 2007. 305p.

RAIJ, B.van. Fertilidade do solo e adubação. Piracicaba, Ceres, 1991. 343p.
REIS, G.L.; LANA, A.M.Q.; LANA, R.M.Q.; SILVA, A.A. \& MOREIRA, G.H.F.A. Sombreamento e fertilização nitrogenada sobre atributos químicos de solo em uma pastagem de Brachiaria brizantha cv. marandu. R. Bras. Agric. Sust., 1:50-58, 2011.

ROCHETTE, P.; MACDONALD, J.D.; ANGERS, D.; CHANTINI, M.H.; GASSER, M. \& BERTRAND, N. Banding urea increased ammonia volatilization in a dry acidic soil. J. Environ. Qual., 38:1383-1390, 2009.

ROSOLEM, C.A.; FOLONI, J.S.S. \& OLIVEIRA, R.H. Dinâmica do nitrogênio no solo em razão da calagem e adubação nitrogenada, com palha na superfície. Pesq. Agropec. Bras., 38:301-309, 2003.

SARMENTO, P.; RODRIGUES, L.R.A.; CRUZ, M.C.P.; LUGÃO, S.M.B.; CAMPOS, F.P.; CENTURION, J.F. \& FERREIRA, M.E. Atributos químicos e físicos de um Argissolo cultivado com Panicum maximum Jacq. cv. IPR-86 Milênio, sob lotação rotacionada e adubado com nitrogênio. R. Bras. Ci. Solo, 32:183-193, 2008.

SILVA, S.C.; BUENO, A.A.O.; CARNEVALLI, R.A.; UEBELE, M.C.; BUENO, F.O.; HODGSON, J.; MATTHEW, C.; ARNOLD, G.C. \& MORAIS, J.P.G. Sward structural characteristics and herbage accumulation of Panicum maximum cv. Mombaça subjected to rotational stocking managements. Sci. Agric., 66:8-19, 2009.

SOUZA, D.M.G.; MIRANDA, L.N. \& OLIVEIRA, S.A. Acidez do solo e sua correção. In: NOVAIS, R.F.; ALVAREZ V., V.H.; BARROS, N.F.; FONTES, R.L.F.; CANTARUTTI, R.B. \& NEVES, J.C.L., eds. Fertilidade do solo. Viçosa, MG, Sociedade Brasileira de Ciência do Solo, 2007. p.205274.

SAS Institute. STATISTICAL ANALYSIS SYSTEM - SAS. SAS Language reference. Version 6. Cary, 1993. 1042p.

TASCA, F.A.; ERNANI, P.R.; ROGERI, D.A.; GATIBONI, L.C. \& CASSOL, P.C. Volatilização de amônia do solo após a aplicação de ureia convencional ou com inibidor de urease. R. Bras. Ci. Solo, 35:493-502, 2011.

TEIXEIRA FILHO, M.C.M.; BUZETTI, S.; ANDREOTTI, M.; ARF, O. \& BENETT, C.G.S. Doses, fontes e épocas de aplicação de nitrogênio em trigo irrigado em plantio direto. Pesq. Agropec. Bras., 45:797-804, 2010.

VALE, D.W. Efeito da aplicação de nitrogênio nos atributos químicos do solo, na nutrição e na produção de cana-deaçúcar. Jaboticabal, Universidade Estadual Paulista "Júlio de Mesquita Filho”, 2009. 120p. (Dissertação de Mestrado)

WHITEHEAD, D.C. Grassland nitrogen. Wallingford, CAB International, $1995.397 \mathrm{p}$. 